syndrome pts (15,3 per 100 patient-years). The probability of EN recurrence in Löfgren syndrome pts was significantly higher in subjects older than 40 y (OR 3,$81 ; p=0,03$ ), in subjects with late ( $\geq 3$ months from $E N$ onset) initiation of treatment (OR 8,94; $\mathrm{p}=0,0008$ ) and in subjects with indurations $>5 \mathrm{~cm}$ in size (OR $3,65 ; p=0,03)$. The probability of LDS recurrence was significantly higher in pts with confluent nodules, forming conglomerate masses (OR 4,33; $p=0,037$ ), and pts taking hydroxychloroquine at $\leq 200 \mathrm{mg} /$ day during $\geq 6$ months (OR 5,25 ; $\mathrm{p}=0,019$ ).

Conclusions: Comprehensive examination is needed to identify the clinical type of $\mathrm{Pn}$. Symmetrical involvement of all extremities is characteristic for EN in young subjects. Asymmetric nodular rash over lower extremities in subjects with abnormal BMI and CVI is specific for LDS. CWD usually presents with nodular rash on the trunk. Identified risk factor for EN and LDS recurrence should be taken into consideration while writing a treatment plan.

Acknowledgements: The study had no sponsorship.

Disclosure of Interest: None declared

DOI: 10.1136/annrheumdis-2018-eular.2280

\section{AB1133 ROLE OF THE RHEUMATOLOGIST IN A REGIONAL REFERENCE HAEMOPHILIA UNIT}

C. Aguilera $\operatorname{Cros}^{1,1}$, M. Arcila Durán ${ }^{1}$, L. Mendez Díaz ${ }^{1}$, A. Ruiz Román ${ }^{1}$ N. Garrido Puñal', R. Nuñez Vázquez ${ }^{2}$, J. Povedano Gómez ${ }^{1} .{ }^{1}$ Rheumatology; ${ }^{2}$ Haematology, University Hospital Virgen del Rocío, Seville, Spain

Background: Haemophilia is an X-linked hereditary bleeding disorder caused by deficiency in coagulation factor VIII (FVIII), in haemophilia A (HA), and factor IX in haemophilia $B(\mathrm{HB})$.

They are classified as severe, moderate or mild, depending on the level of coagu lation factor deficiency. Men are affected clinically by the disease, and women who are carriers, usually remain asymptomatic.

$\mathrm{HA}$ is more common than $\mathrm{HB}$ (from $80 \%$ to $85 \%$ of all cases).

Their bleeding complications primarily affect the musculoskeletal system. Hemarthrosis is the major hemophilia-related complication, responsible for a particularly debilitating chronic arthropathy, in the long term, affecting mainly the load joints (knees, ankles and elbows).

In addition to clotting factor concentrates, usually prescribed by the haematologist, The management of acute hemarthrosis and chronic arthropathy requires a close collaboration with rheumatologists. This collaboration is the key to effectively preventing hemarthrosis, managing acute joint bleeding episodes, assessing joint function, and actively treating chronic arthropathy.

Objectives: To analyse the clinical characteristics, extent of joint involvement and associated comorbidity of a cohort of patients with hemophilic arthropathy. Methods: This is a retrospective study, carried out in the Haemophilia Unit of our hospital (regional reference), in patients with moderate to severe haemophilia $A$ and $B$, with hemophilic arthropathy, seen in consultation with episodes of joint bleeding (2007-2017). Severity of haemophilia was defined based on determined by the percentage of FC activity (VIII and IX), moderate from $1 \%$ to $5 \%$, severe $<1 \%$. The number of episodes of hemarthros was collected in the 3 months before and after the radioisotopic synoviorthesis (intra-articular injection of a colloidal suspension of particles marked with a radioisotope, whose objective is the destruction of the synovial membrane).

Results: We included 88 patients ( 87 men and 1 symptomatic carrier woman with decreased levels of factor VIII), mean age $31 \pm 17$ years. HA (severe $56 \%$, moderate $26 \%$ ), HB (severe $14 \%$, moderate $1 \%$ ). The target joint: knee $51 \%$, followed by ankle $26 \%$, elbow $13 \%$ and other $7 \%$ ( 5 shoulders and 2 wrists). In 61 patients, magnetic resonance imaging (MRI) was performed: synovial hypertrophy $9 \%$, hemosiderin deposits (in acute stage of joint bleeding) $2 \%$ and structural alteration (erosions and subchondral cysts, loss of focal cartilage) $68 \%$. A radioisotope synoviorthesis was made to 18 patients: 12 with sulfide 186 Re colloidal (5 ankles, 4 knees, 2 elbows) and 6 with $90 \mathrm{Y}$ colidal citrate ( 4 knees, 3 ankles), having a decrease of $74 \%$ (range $59 \%-100 \%$ ) in the number of hemarthrosis in the 3 subsequent months. Total knee replacement was needed in $13 \%$ of the patients $(7$ with $\mathrm{HCV}$ liver disease and in $6 \mathrm{HCV}$ liver disease and coexistence with HIV). They have infection due to HCV $33 \%$, HIV $25 \%$ and HBV $6 \%$.

Conclusions: This study highlights the extent of joint damage in haemophiliac patients as well as the high comorbidity of HCV and HIV infections.

The experience of a monographic Haemophilia consultation, with the participation of different specialties (being fundamental the rheumatologist), benefits the multidisciplinary approach of these patients, being the results obtained in our series concordant with the described in the literature.

Disclosure of Interest: None declared

DOI: 10.1136/annrheumdis-2018-eular.3561

\section{$\mathrm{AB} 1134$ DETERMINING FACTORS OF SEVERITY IN HEMOPHILIC ARTHROPATHY}

C. Aguilera $\operatorname{Cros}^{1}$, L. Méndez Díaz ${ }^{1}$, M. Arcila Durán ${ }^{1}$, A. Ruíz Román ${ }^{1}$, M. J. Valenzuela Porcel ${ }^{1}$, N. Garrido Puñal ${ }^{1}$, J.P. Sanchez Serrano ${ }^{2}$, R. Nuñez Vazquez ${ }^{3}$, J. Povedano Gómez ${ }^{1}$. ${ }^{1}$ Rheumatology, University Hospital Virgen del Rocío, Seville; ${ }^{2}$ Animal Breeding and Genetics, IRTA Caldes de Montbui, Barcelona; ${ }^{3}$ Haematology, University Hospital Virgen del Rocío, Seville, Spain

Background: In patients with haemophilia, the development of inhibitors to factor VIII/IX (Haemophilia A and B, HA/HB), prevents adequate replacement therapy and results in increased risk of serious bleeding episodes, poor control of joint bleeding, and progressive, debilitating joint disease.

Objectives: To describe, according to the Arnold-Hilgartner scale (AHRS), the radiological findings in a cohort of hemophilic arthropathy (HArth) patients and to analyse the relationship that may exist between the degree of joint involvement and $\mathrm{HA} / \mathrm{HB}$, severity, age and presence or absence of inhibitor.

Methods: This is a retrospective study, carried out in the Haemophilia Unit of our hospital, in patients with HArth (2007-2017). Severity of haemophilia: percentage of coagulation factor (CF) activity, moderate $(1 \%-5 \%)$ and severe $<1 \%$. The AHRS includes 5 levels.

For the study of the association of the type and degree of haemophilia; and the presence of inhibitor, with the level in the AHRS, a linear model was used. The significance in this regard of the linear contrasts of interest was studied using $F$ tests, defining the first species error at 0.05 .

Results: We included 88 patients. Characteristics of the patients in the attached chart. No significant association was detected between the type and severity of haemophilia with the development of inhibitor.

The results of the linear model only showed association $(p=0.01)$ between the severity of haemophilia and AHRS, patients with moderate haemophilia presented a least square mean for the AHRS of $2.6(0.3)$, whereas the serious ones had a value of $3.4(0.2)$. The least squared means for patients with $\mathrm{HA}$ and $\mathrm{HB}$ were $2.9(0.2)$ and $3.1(0.4)$ respectively, the contrast did not reach statistical significance ( $p>0.1)$, and the same occurred between patients who had generated or not inhibitor 2.8 (0.2) Vs 3.1 (0.3). Apart from the severity of haemophilia, the other factor that showed a significant and significant effect $(p<0.001)$ on the AHRS values was age. The estimated value for the regression coefficient of age on the radiological status was $0.05(0.009)$.

Abstract AB1134 - Table 1

\begin{tabular}{lc}
\hline Type of Haemophilia & \\
\hline Haemophilia A $\mathrm{n}(\%)$ & $73(82 \%)$ \\
Haemophilia B $\mathrm{n}(\%)$ & $14(15 \%)$ \\
Severity of Haemophilia & \\
Haemophilia A severe $\mathrm{n}(\%)$ & $50(56 \%)$ \\
Haemophilia A moderate $\mathrm{n}(\%)$ & $23(26 \%)$ \\
Haemophilia B severe $\mathrm{n}(\%)$ & $13(14 \%)$ \\
Haemophilia B moderate $\mathrm{n}(\%)$ & $1(1 \%)$ \\
Age m (SD) & $31(17)$ \\
Development of inhibitors to factor VIII/IX $\mathrm{n}(\%)$ & $16(18 \%)$ \\
Haemophilia A severe with inhibitors $\mathrm{n}(\%)$ & $10(11 \%)$ \\
Haemophilia A moderate with inhibitors $\mathrm{n}(\%)$ & $3(3 \%)$ \\
Haemophilia B severe with inhibitors $\mathrm{n}(\%)$ & $3(3 \%)$ \\
AHRS scale $1 \mathrm{n}(\%)$ & $18(20 \%)$ \\
AHRS scale $2 \mathrm{n}(\%)$ & $17(19 \%)$ \\
AHRS scale $3 \mathrm{n}(\%)$ & $18(20 \%)$ \\
AHRS scale $4 \mathrm{n}(\%)$ & $15(17 \%)$ \\
AHRS scale $5 \mathrm{n}(\%)$ & $19(21 \%)$ \\
\hline
\end{tabular}

Conclusions: Contrary to what has been observed in other studies, in our cohort it does not seem that the presence of inhibitor or the type of haemophilia has a negative effect on the severity of the radiological findings. The age and severity of haemophilia do seem to influence the radiological stage.

Disclosure of Interest: None declared

DOI: 10.1136/annrheumdis-2018-eular.3542

\section{AB1135 CARDIAC MAGNETIC RESONANCEFINDINGS IN PATIENTS WITH BIOPSY-PROVEN VIRUS-NEGATIVE LYMPHOCYTIC MYOCARDITIS}

C. Campochiaro, G. De Luca, S. Sartorelli, C. Candela, G. Cavalli, L. Dagna. Unit of Immunology, Rheumatology, Allergy and Rare Diseases, IRCCS San Raffaele Hospital, Milan, Italy

Background: Cardiac magnetic resonance (CMR) is considered to be useful for non-invasive myocarditis diagnosis. Lake Louise Criteria(LLC) has been proved to have moderate accuracy in the diagnosis of acute or chronic myocarditis 1. Objectives: to describe the CMR findings in patients with virus-negative lymphocytic myocarditis(VNLM) from a large monocentric Italian cohort. 